\title{
Um estudo sobre as Competências Gerenciais na Administração Pública: O caso dos Gestores do Judiciário Brasileiro
}

\author{
Francisco Georgi de Souza ${ }^{1}$; Fernanda Roda de Souza Araújo Cassundé2
}

\begin{abstract}
Resumo: Este trabalho teve como fundamento diagnosticar as competências de gestores das Unidades Judiciárias de três órgãos, quais sejam Tribunal de Justiça de Pernambuco, Tribunal de Justiça da Bahia e Tribunal Regional Federal, delimitados na área do sertão pernambucano e na cidade de Juazeiro-BA. Com esteio na literatura sobre gestão baseada em competências e sobre competências gerenciais, especialmente voltada para a administração pública, buscou-se identificar quais as competências que, na visão de gestores das unidades judiciárias, são as mais importantes para a organização e qual o nível de domínio que esses gerentes apresentam sobre tais competências. Estabelecendo-se correlação entre importância e domínio, buscou-se a identificação das prioridades de desenvolvimento e a identificação das lacunas de competência. A pesquisa de teor quantitativo teve como amostra o total de 30 indivíduos extraída de 34 questionários enviados a 07 comarcas do Sertão de Pernambuco, à Comarca de Juazeiro, e ainda ao Tribunal Regional Federal da $5^{\text {a }}$ Região. A partir da análise dos dados, observou-se que as competências consideradas mais importantes e de maior domínio são aquelas que diz respeito à administração pública voltada para a satisfação do usuário da justiça, à observância dos princípios constitucionais, e as referentes à postura e à gestão pública baseada na ética.
\end{abstract}

Palavras-chave: Gestão baseada em competências; competências gerenciais; gestão pública; Judiciário.

\section{A study of managerial skills in public administration: the case of Brazilian judiciary managers}

\begin{abstract}
This work was based diagnose the skills of managers of Judicial Units three organs, namely the Court of Pernambuco, Bahia Court and Federal Court, defined in the Pernambuco backwoods area and the city of Juazeiro-BA. With mainstay in the literature on management based on skills and on managerial skills, especially toward the government, we sought to identify the skills that, in the view of managers of judicial units are the most important to the organization and what level of domain that these managers have on these skills. Establishing a correlation between importance and domain, we sought to identify development priorities and identification of competence gaps. The quantitative content of research was to sample the total of 30 individuals from 34 questionnaires sent to 07 districts of the Hinterland of Pernambuco, the District of Juazeiro, and yet at the Federal Regional Court of the 5th Region. From the data analysis, it was observed that the competences considered most important and largest area are those regarding the public administration focused on user satisfaction of justice, observance of constitutional principles, and those related to posture and governance based on ethics.
\end{abstract}

Keywords: Competency-Based Management; management skills; public administration; Judiciary.

\footnotetext{
${ }^{1}$ Graduação em Licenciatura em Matemática pela Faculdade de Formação de Professores de Petrolina;

${ }^{2}$ Doutora, Mestre e Bacharel em Administração - UFPE. Atualmente é professora Adjunta I do colegiado de Administração da Universidade Federal do Vale do São Francisco - UNIVASF e Pesquisadora de projeto apoiado pelo CNPq cujo tema refere-se ao desenvolvimento de competências docentes para EAD. Avaliadora ad hoc da FACEPE - Fundação de Amparo à Ciência e Tecnologia do Estado de Pernambuco. Líder do GP: CEOS - Centro de Estudos Organizacionais do Semiárido.E-mail: Fernanda.roda@univasf.edu.br.
} 
Id on Line Revista Multidisciplinar e de Psicoloqia

Id on Line Revista Multidisciplinar e de Psicologia

\section{Introdução}

Bourdieu (2004), discorrendo sobre o papel do Judiciário, diz que esse poder teve seu papel limitado no "campo jurídico" que é o lugar de concorrência pelo monopólio de dizer o direito, no qual consiste essencialmente na capacidade de interpretar um corpus de texto que consagra a visão legítima do mundo social. No entanto, somente a capacidade de interpretar não o credenciava como Poder.

No atual Estado Contemporâneo os questionamentos das funções do Poder Judiciário se acentuaram no sentido de procurar a satisfação das necessidades essenciais de sobrevivência do ser humano que se traduzem na solução de conflitos por meio da aplicação efetiva de normas legais com imparcialidade e buscar soluções efetivas que assegurem direitos sociais e influencie diretamente no crescimento sócio-econômico dos cidadãos. De acordo com Cunha (1999) uma das razões por que o Judiciário vem se firmando como verdadeiro poder, é justamente pela inquestionável demonstração da sua capacidade de interferir com legitimidade eficiencia na vida social, política e econômica do Estado.

Assim, dentro dessa dinâmica de transformação e progresso orbitam os servidores do Poder Judiciário, personagens essenciais na boa administração da Justiça. Suas atividades são reguladas nos Códigos de Processo Penal e Civil, leis federais esparsas, a exemplo da Lei 5.010/66 e em Códigos de Organização Judiciária Estaduais.

Para uma efetiva mudança nos rumos gerenciais da gestão pública, os agentes de transformação, gestores públicos, precisam desenvolver competências objetivando o desenvolvimento social. Assim, diferentemente das empresas do setor privado, em que a ideia de competências está vinculada à efetividade, ao desempenho econômico-financeiro e à competitividade, nas organizações públicas o desenvolvimento dos servidores está vinculado à efetividade, na mobilização de recursos e na prestação de serviço direcionados para o interesse público e o bem-estar social.

Nesse sentido, nas duas últimas décadas, o serviço público tem absorvido e aplicado algumas práticas do setor privado em sua dinâmica gerencial (LIMA; SILVA, 2015). Características exigidas do trabalhador no setor privado como proatividade, habilidade para trabalhar em equipe, capacidade de adaptação, criatividade, pensamento crítico e familiaridade com as tecnologias da informação passam a ser requeridas também do servidor público, dessa vez não de acordo com um contexto mercadológico, mas, sim, no intento de preparar-se para servir melhor a sociedade.

Os gestores das secretarias dos órgãos judiciários, de forma geral, têm um papel fundamental nas transformações necessárias dos processos de trabalho para a boa prestação jurisdicional, seu papel constitui "processo de influência, geralmente de uma pessoa, por meio do qual um indivíduo ou grupo é orientado para o estabelecimento de metas" (BOWDITCH e BUONO, 2002, p. 118).

Portanto, buscar o espírito de coletividade e coordenação para fomentar a tomada de decisão da equipe, sobretudo a coesão voltada para o alcance dos objetivos organizacionais preponderantemente 
Id on Line Revista Multidisciplinar e de Psicologia

Id on Line Revista Multidisciplinar e de Psicologia

passa pela influência positiva do líder junto ao seu grupo. Gayotto e Domingues (1995) aponta a lideranção como responsável pela geração de um clima em que todos queiram contribuir para a produção eficiente e eficaz, provocando o interesse nos liderados em aprender recursos técnicos e teóricos para resolver os problemas e efetuar melhorias.

Segundo Le Boterf (2003), o desenvolvimento de uma competência coletiva depende do conhecimento compartilhado para coagir e coproduzir. Isso demanda a necessidade de disponibilizar as competências individuais para que a equipe coordene de forma adequada as atividades. A existência de um espírito colaborativo é condição para a construção de um saber coletivo. As pessoas unem suas diferenças em um sentido de complementaridade, além de buscarem obter juntas os conhecimentos, como um conjunto integrado.

Nesse contexto a aprendizagem decorrente do trabalho é formada por pessoas com habilidades complementares e consiste na interação das visões, por meio do confronto de ideias (Lima e Silva, 2015). Sendo assim, não é necessário que haja afinidade pessoal para realização de um projeto, mas deve existir uma convivência saudável em que prevaleça um exercício contínuo de comunicação, diálogo, negociação, gestão de conflitos e motivação. Ou seja, cabe ao Gestor/Chefe/Diretor de Secretaria fomentar essa comunicação sem barreiras entre os demais servidores, para que haja um ambiente de respeito e interação com abertura para o desenvolvimento da diversidade de pensamentos objetivando o bem estar dos próprios servidores e a boa prestação jurisdicional.

O modelo de gestão baseado em competências ganha destaque, no cenário da Administração Pública com a edição do Decreto ${ }^{\circ}$. 5.707, de 23 de fevereiro de 2006, que institui a política nacional de desenvolvimento de pessoal, tornando-se um referencial para a gestão de pessoas. Destaca-se também, na política, a noção de gestão por competência como gerenciamento de capacitação voltado para o desenvolvimento do emaranhado de conhecimentos, habilidades e atitudes essenciais para um bom desempenho das atribuições funcionais, visando alcançar as metas da instituição. (Santos 2014).

Para Zarifian (2001, p 72) ), "a competência é um entendimento prático de situações que se apoia em conhecimentos adquiridos e os transforma na medida em que aumenta a diversidade de situações". O conhecimento adquirido pelo gestor no ambiente profissional será fundamental para a atuação em cada caso particular, na medida que as diversidades de problemas e imprevistos são reais e precisam ser administrados de forma bem articulada e eficiente, compreendendo os elementos tanto materiais, tanto o elemento humano com toda sua subjetividade e imprevisibilidade.

Diante disso, com o intuito de se consumar aos objetivos desse estudo, o presente artigo aborda as competências necessárias para uma boa gestão no judiciário, e procura identificar as competências individuais que são observadas como importantes para os gestores do Judiciário Estadual e Federal localizado no Sertão Pernambucano, bem assim o domínio desses gestores em relação às competências apresentadas. 
Id on Line Revista Multidisciplinar e de Psicologia

Id on Line Revista Multidisciplinar e de Psicologia

Assim, espera-se contribuir para um melhor aprendizado no âmbito dessa temática, mapeando a percepção do que seja mais ou menos importante nas tarefas conferidas aos gestores e as competências de maior ou menor domínio, conscientizando que a identificação da ausência de formação, vai viabilizar um investimento em capacitação mais pontual, visando ao desenvolvimento de competências gerenciais dos serventuários da Justiça.

\section{Conceito de Competência no Trabalho}

No passado o conceito de Competência não passava de um conceito instrumental para processos de recrutamento, seleção e suporte à avaliação de desenvolvimento e potencial. Segundo Palharini (2008), no século XIX, os esforços das empresas estavam dirigidos para a racionalidade administrativa e sistemas de trabalho.

A teoria gerencial de Taylor baseava-se na fragmentação dos processos de trabalho em porções que permitiam maior racionalidade e padronização do processo. Com a padronização se atingia graus significativos de especialização, permitindo identificar e isolar habilidades e características individuais. Nesta época a seleção estava orientada para a relação direta entre o desempenho e as habilidades motoras.

Outras variáveis como de caráter motivacional não eram consideradas. Buscava-se "o que fazer" e "uma melhor maneira" de fazer as tarefas, delineando o cargo. As caracterísiticas pessoais avaliadas no processo de recrutamento e seleção de trabalhadores configuravam um perfil obediente e disciplinado. O trabalhador, confinado a um cargo isolado e submetido aos controles administrativos, às regras, às imposições e à hierarquia, era impedido de atuar como pessoa "detentora de qualidades contextualizadas em situação de trabalho, tais como curiosidade, rigor, reatividade", como aponta Le Boterf, (2003, p.124).

Nos anos 90 começou a tomar forma um modelo estruturado de gestão de pessoas, que tem como peculiaridade considerar a "participação dos funcionários" como sendo "essencial para que a empresa implemente sua estratégia e crie vantagem competitiva" (LAWLER III, 1998: 12 apud Albuquerque e Oliveira 2001).

É assim que, conforme Palharini (2008), no paradigma contemporâneo, as atividades de recrutamento e seleção não mais possuem como principal característica a busca pelo trabalhador que execute apenas uma função específica, estática, dentro da empresa. A utopia agora é encontrar o homem certo para lugares incertos. O objetivo é que as pessoas sejam selecionadas para uma carreira em longo prazo na empresa e não simplesmente para ocupar um cargo específico em curto prazo. $\mathrm{O}$ enfoque agora está nas pessoas e em suas competências. O mapeamento dessas competências possibilita as escolhas estratégicas feitas pela empresa. 
Id on Line Revista Multidisciplinar e de Psicologia

Id on Line Revista Multidisciplinar e de Psicologia

Nas palavras de Tomasi (2004, p.11):

[...] a competência nos impõe ajustar o foco de nosso estudo sobre o indivíduo [...] que, produzido nas relações sociais nas quais se encontra inserido, insiste em guardar suas diferenças em relação aos outros, [...] exige uma proximidade, uma intimidade com suas subjetividades, seus saberes, seus valores, suas crenças e seus princípios, que motivam e dão materialidade às suas ações no cotidiano.

Em síntese, com a tendência à delegação ao trabalhador de responsabilidade pela própria formação e autonomia no trabalho, o controle exercido pela gerência taylorista-fordista esvaneceu. Esse fato levou à demanda de um perfil profissional autônomo, responsável, e à mudança na cultura das empresas, buscando estimular e apoiar a iniciativa das pessoas, a criatividade e a busca autônoma de resultados para a organização (DUTRA, 2004). Aumentaram as exigências referentes às características individuais dos trabalhadores, em contexto de trabalho, tais como iniciativa, criatividade, autonomia, responsabilização. Essa tendência gerou mudanças no processo de recrutamento e seleção de trabalhadores, até então centrado nos princípios do cargo e da pessoa certa para o cargo certo.

De acordo com Santos (2014), O conceito de competências surge com o desenvolvimento de capacidades que podem ser mobilizadas em situações, em sua maioria, pouco previsíveis. A noção de competência compatibiliza-se com o conceito de evento proposta por Zarifian (2001). A imprevisibilidade do evento está relacionado a novos usos e novos processos que fazem parte do cotidiano de uma organização. Logo, a base da abordagem de competência deixa de ser o desenho dos cargos e passa a ser o conceito dinâmico de habilidades e competências necessárias ao sucesso da organização e de seus parceiros.

$\mathrm{Na}$ literatura identificamos a abordagem de alguns autores que falam da competência não somente como um conjunto de qualificações que um indivíduo detém, mas também como o resultado ou efeito de tais qualificações aplicadas ao ambiente de trabalho. Le Boterf (1999) afirma que cada ação competente é produto de uma combinação de recursos e é no saber mobilizar e aplicar esses recursos que reside à riqueza profissional, ou seja, a competência.

Nos últimos anos a gestão por competência tornou-se essencial no modelo de gestão de pessoas, criando possibilidades concretas para novas formas de relacionamento entre pessoas, seu trabalho e a Organização, onde as expectativas de ambas as partes podem ficar mais claras e transparentes, baseada na troca entre os saberes da organização e do indivíduo Existe uma grande diversidade de conceitos para explicar o que é Competência.

Fleury e Fleury (2004), sintetiza o conceito de competências como um " conjunto de conhecimentos, habilidades, atitudes que afetam a maior parte do trabalho de uma pessoa, e que relacionama com o desempenho no trabalho..." 
Id on Line Revista Multidisciplinar e de Psicoloqia

Id on Line Revista Multidisciplinar e de Psicologia

O conceito de competência no contexto organizacional começou a ser elaborado sob a perspectiva do indivíduo, sendo assim tal conceito passa a ser analisado como um conjunto de conhecimentos, habilidades e atitudes que justificam um alto desempenho, na medida em que há também um pressuposto de que os melhores desempenhos estão fundamentados na inteligência e na personalidade das pessoas, considerando, portanto, a competência como um estoque de recursos que o indivíduo detém. Esse conceito se confunde com o conceito de qualificação, que usualmente é definida pelos requisitos associados à posição, ou ao cargo, ou pelos conhecimentos da pessoa. (Fleury e Fleury 2004). No entanto, a competência vai mais além, nas palavras de Zarifian (1994) "refere-se à capacidade de a pessoa assumir iniciativas, ir além das atividades prescritas, ser capaz de compreender e dominar novas situações no trabalho, ser responsável e ser reconhecido por isso" (Zarifian, 1994, p. 111 apud Fleury e Fleury 2004).

Ainda nessa vertente, Mertens (1996) afirma que, o conceito de competência compreende conhecimento e habilidades constatadas. Existe diferença entre habilidades e conhecimentos mostrados no posto de trabalho e os resultados exigidos de uma pessoa que ocupa esse posto. Enquanto qualificação se projeta no desempenho do posto, em saber cumprir as normas de conhecimento e habilidade, a competência se projeta no resultado que deve cumprir a pessoa ligada ao posto, tais como conhecimentos e habilidades que assegurem um produto desejado. Enquanto a qualificação se circunscreve ao posto, a competência se centra na pessoa, que pode chegar a ocupar um ou mais postos de trabalho, o que subjaz no conceito de multifunção.

A competência é a forma inteligente de lidar com as situações a partir dos conhecimentos adquiridos que se avolumam e ganha força à medida em que aumenta a complexidade dos problemas, não estando contida nas predefinições de determinada tarefa.

Nas palavras de Fleury e Fleury (2004), citando Boterf (1994), competência é um saber agir responsável, como tal conhecido pelos outros. Sugere saber como mobilizar, integrar recursos e transferir os conhecimentos, recursos e habilidades, num contexto profissional determinado.

As competências são sempre contextualizadas, não há que se falar em competência sem que haja comunicação, sendo os conhecimentos adquiridos reconhecidos como competência apenas quando são trocados e comunicados. E acima de tudo, tais competências devem agregar valor econômico para a organização e valor social para o indivíduo.

Sendo assim poderemos concluir que o conceito de competência converge segundo Zarifian (2001) para se articular tridimensionalmente: Conhecimentos, habilidades e atitudes, ou seja, é o saber o quê e por que faz; saber decidir; saber mobilizar pessoas e recursos materiais; saber comunicar de forma clara e compreensível; saber aprender, trocando conhecimentos; saber comprometer, engajando-se como os outros e com os objetivos da organizações; saber assumir responsabilidades e finalmente, ter visão estratégica da organização para entender o seu negócio e identificar as oportunidades. 
Id on Line Revista Multidisciplinar e de Psicoloqia

Id on Line Revista Multidisciplinar e de Psicologia

Para desempenhar a complexa função gerencial cada gestor deve dispor de um conjunto de competências gerenciais. A competência pode ser percebida como um estoque de recursos (conjunto de conhecimentos, habilidades e atitudes) que o indivíduo detém (Fleury e Fleury, 2004).

São várias as correntes que tentam explanar o conceito apropriado para competências, que na verdade se complementam para melhor explicar o conceito geral de competência. Segue abaixo um quadro com a sintese de cada teórico na visão de Streit (2001).

Quadro 1 - Conceitos de competência

\begin{tabular}{|l|l|l|}
\hline \multicolumn{1}{|c|}{ Autores } & \multicolumn{1}{|c|}{ Conceito } & \multicolumn{1}{|c|}{ Ênfase } \\
\hline $\begin{array}{l}\text { Lê Boterf (1999, } \\
\text { p. 109) }\end{array}$ & $\begin{array}{l}\text { Saber mobilizar e combinar os recursos pessoais } \\
\text { (conhecimentos, habilidades, atitudes) e os recursos } \\
\text { do seu ambiente, de maneira pertinente, em uma } \\
\text { situação específica. }\end{array}$ & $\begin{array}{l}\text { Combinação de recursos } \\
\text { para a ação em contextos } \\
\text { variados. }\end{array}$ \\
\hline $\begin{array}{l}\text { Fleury e Fleury } \\
(2004, \text { p. 30) }\end{array}$ & $\begin{array}{l}\text { saber agir responsável e reconhecido, que implica } \\
\text { mobilizar, integrar, transferir conhecimentos, } \\
\text { recursos, habilidades, que agreguem valor } \\
\text { econômico à organização e valor social ao indivíduo. }\end{array}$ & $\begin{array}{l}\text { Agregação de valor } \\
\text { econômico e social. }\end{array}$ \\
\hline Parry (1998, p. 60) & $\begin{array}{l}\text { Cluster de conhecimentos, atitudes e habilidades } \\
\text { relacionadas que influem na realização de uma } \\
\text { atividade. }\end{array}$ & Performance no trabalho. \\
\hline $\begin{array}{l}\text { Zarifian (2001, p. p. } \\
\text { 68) }\end{array}$ & $\begin{array}{l}\text { Competência é "o tomar iniciativa" e "o assumir } \\
\text { responsabilidade" do indivíduo diante de situa- ções } \\
\text { profissionais com as quais se depara. }\end{array}$ & $\begin{array}{l}\text { Entendimento prático de } \\
\text { situações complexas }\end{array}$ \\
\hline
\end{tabular}

Fonte: Streit (2001).

Todos os conceitos supramencionados no quadro de Streit (2001) se correlacionam e serão fonte para o presente estudo, vez que a fusão desses conceitos exclarecem melhor o conceito geral de competência, tendo em vista que em qualquer instituição as ênfases mencionadas são presentes e carecem das competências, tais como a mobilização, conhecimento, habilidades, integração, atitude, enfim, proatividade diante das situações complexas inerentes a toda instituição.

\section{Gestão por Competência}

Para o enfrentamento das dificuldades inerentes a qualquer empresa, estas precisam de profissionais atuando com iniciativa, indo além do prescrito, a todo tempo fazendo escolhas e tomando decisões, ao invés de indivíduos restringidos ao desempenho de tarefas pré-definidas em uma descrição de cargo (LE BOTERF, 2003).

Fleury e Fleury (2004), dizem que a gestão baseada em competência emerge de um contexto organizacional de muitas mudanças e transformações caracterizadas por alguns elementos tais como:

- Busca por resultados ótimos;

- Sistemática minimização de custos operacionais e pessoais; 
Id on Line Revista Multidisciplinar e de Psicoloqia

Id on Line Revista Multidisciplinar e de Psicologia

- Permanentes transformações sociais e produtivas;

- Lógica que privilegia a mensuração e reduz significativamente a importância da

- Subjetividade como critério de valor;

- Forte pressão ambiental sobre as organizações impondo profundas reformulações;

- Incorporação de novas tecnologias organizacionais;

- Adoção de práticas gerenciais como a terceirização e o downsizing gerencial;

- Contínua busca por melhoria na qualidade e na produtividade;

- Ênfase na figura do cliente;

- Valorização do indivíduo, que passa a ser vista como premissa imprescindível;

- Incorporação da gestão de competências como prática corrente do gerenciamento

- Cotidiano e estratégico das pessoas no interior da organização;

- Gestão de competências que vem acompanhada de forte reflexão sobre seu papel na

- Interligação entre produção e educação.

Para Cunha et al (2014), com esteio nas palavras de Carbone (2006), a gestão por competências tem como fundamento a orientação no sentido de buscar o planejamento, captação, desenvolvimento e avaliação das competências nos diferentes níveis da organização com vistas à consecução dos seus objetivos, impondo-se assim três competências básicas denominadas competência técnica, individuais e organizacionais, as quais trabalham em conjunto para gerar outras competências.

Diante de uma cenário de enorme competitividade, o gestor deve gerir a concorrência através da assimilação de informações, visando a obtenção de vantagens competitivas; gerir a complexidade envolvida no dia a dia da Organização e seus concorrentes; gerir a adaptabilidade, inovando e buscando a melhoria constante de estratégias e processos; gerir equipes identificando e respeitando as diferenças; gerir incertezas, sabendo lidar com as modificações repentinas; e gerir o aprendizado, aprendendo e educando a equipe (Almeida e Motta, 2012). Estes autores ainda acrescentam que é necessário ao gestor que ele tenha conhecimento sobre aspectos técnicos e do negócio, capacidade conceitual necessária para lidar com a complexidade organizacional, flexibilidade para lidar com as mudanças ambientais, cada vez mais aceleradas, sensibilidade para conduzir diferenças individuais presentes na equipe, que é a capacidade de conseguir a unidade na diversidade, capacidade de julgamento e decisão em situações de incerteza e capacidade de reflexão, que significa uma predisposição ao aprendizado contínuo.

Teixeira (2006) observa que a conveniência de que o modelo de gestão baseada em competências seja amplo e flexível, para adaptar-se a um ambiente dinâmico, em constante mutação, sendo que tais mudanças podem ocorrer em períodos muito curtos. 
Id on Line Revista Multidisciplinar e de Psicologia

Id on Line Revista Multidisciplinar e de Psicologia

O modelo de gestão por competência possibilita que todas as áreas da organização desenvolvam conhecimentos, habilidades, atitudes que possibilitem alcançar as competências organizacionais determinadas. Assim, empresas e pessoas estarão agrupadas, propiciando um processo contínuo de desenvolvimento de competências, com a organização transferindo seu conteúdo e enriquecendo os seus colaboradores e os preparando para enfrentarem novos desafios profissionais e individuais, e em contrapartida, os colaboradores desenvolverão suas capacidades individuais, transferindo-as para a organização (DANTAS et al, 2011). Percebe-se assim a principal característica da gestão de competências: a organização gerindo seus recursos humanos de acordo com o grau de capacitação alcançado pelos seus colaboradores dentro das competências previstas para cada cargo.

\section{Metodologia}

Este trabalho se configura como quantitativo, uma vez que foram utilizados questionários como instrumentos na coleta de dados, sendo estruturadas perguntas claras e objetivas conforme a perspectiva do método Survey, que na visão de Mello (2013) "é um método de coleta de informações diretamente de pessoas a respeito de suas ideias, sentimentos, saúde, planos, crenças e de fundo social, educacional e financeiro". Esse método foi adotado para possibilitar a participação de gestores de várias comarcas sem a necessidade da presença do pesquisador.

Trata-se de uma pesquisa aplicada, com caráter prático, tendo em vista que poderá subsidiar futuras ações das Unidades Judiciárias dirigidas à solução de necessidades específicas ná área de gestão.

A pesquisa foi realizada em apenas uma etapa: A aplicação de questionário baseado em Teixeira (2006), com as competências gerenciais indicadas e campo para informações relativas a dados sociodemográficos dos gestores questionados. Os sujeitos da pesquisa são os gestores das unidades judiciárias do Sertão Pernambucano. Foram enviados via E-mail para todas a as unidades judiciárias do Tribunal de Justiça do Sertão Pernambucano, para as duas unidades judiciárias do Tribubal Regional Federal, denominado TRF $5^{\text {a }}$ Região, localizado na cidade de Petrolina e também para a comarca de Juazeiro, onde existem 06 unidades judiciárias.

\section{Análise de Dados}

Os questionários foram enviados para 34 unidades judiciárias no sertão pernambucano, nas cidades de Cabrobó, Orocó, Lagoa Grande, Ouricuri, Afrânio, Araripina, Petrolina e ainda na Cidade de Juazeiro-BA, envolvendo 34 gestores. Nas cidades de Petrolina e Juazeiro-BA os questionários 
Id on Line Revista Multidisciplinar e de Psicologia

Id on Line Revista Multidisciplinar e de Psicologia

foram entregues de forma pessoal, com o intuito de obter o máximo de respostas possíveis, tendo em vista haver poucas Unidades Judiciárias e consequentemente poucos Diretores/chefes de secretarias para a amostra da pesquisa.

30 dos 34 gestores contactados responderam os questionários, ou seja, tivemos um aproveitamento de $88,23 \%$.

\section{Perfil dos Respondentes}

A pesquisa foi realizada com 30 Diretores/Chefes de Unidades Judiciárias, dos quais $50 \%$ são do sexo feminino e 50\% do sexo masculino, com faixa etária que varia entre 26 e 65 anos, sendo que 90\% deles com experiência de mais de um ano na função gerencial.

Os órgãos do Judiciário são compostos por cargos da área fim e da área meio ( oficiais de justiça, Psicólogos, Técnicos de TI, Assistentes Sociais e etc), no entanto o objeto de nossa pesquisa envolveu apenas os chefes de unidades judiciárias, que pela natureza da função, são atribuídos aos Analistas Judiciários, Técnicos Judiciários ou Auxiliares Judiciários, todos esses da área fim, sendo inclusive este último extinto para os próximos provimentos de serventuários da justiça.

Na pesquisa 66,66\% responderam ocuparem o cargo efetivo de Técnico Judiciário (nível médio) e 30\% responderam ocuparem o cargo efetivo de Analista Judiciário ( nível superior) e apenas um gestor respondeu ocupar o cargo de Auxiliar Judiciário ( nível fundamental).

Percebe-se que, não obstante a exigência mínima de escolaridade para ascenssão ao cargo efetivo, a maioria dos gestores têm escolaridade acima das exigências do concurso para provimento dos cargo. 33,33\% possuem pós-graduação em nível de especialização e 56,66 possuem graduação, restando apenas $10 \%$ com o ensino médio. Percebe-se ainda que os três que não possuem ensino superior completo, já estão na instituição há mais de 10 anos, portando com bastante experiência nas atividades do judiciário. Isso demonstra um alto grau de escolaridade ou capacitação entre os gestores analisados.

A pesquisa revelou também que não há muita rotatividade no comando das unidades judiciárias $83 \%$ dos Diretores/Chefes de Secretaria têm mais de 6 anos à frente da unidade judiciária e apenas $6,66 \%$ tem menos de 03 anos na função de gestor.

Conclui-se ainda que a maturidade pesa para a escolha do gestor, tendo em vista que 83,33 têm mais de 31 anos de idade. 
Id on Line Revista Multidisciplinar e de Psicologia

Id on Line Revista Multidisciplinar e de Psicologia

\section{Competências Gerenciais Consideradas mais Importantes no Judiciário}

Seguem, na tabela abaixo, as médias e os desvios-padrão respondidos pelos gestores em relação à importância das competências no Judiciário. As competências estão elencadas da maior média de importância para a menor, sendo tanto mais importante a competência quanto maior for a sua média, onde o nível de importância dentro de uma escala de 1 a 5 , significa 1 sem importância" e o 5 "muito importante".

Vale ressaltar que em alguns questionários houve omissões de alguns quesitos por parte dos gestores pesquisados, razão por que, em algumas competências, o quantitativo da amostra, simbolizada pela letra "N" na última coluna da tabela, não completam o total de 30.

Tabela 1 - Importância das competências para os gestores do Judiciário

\begin{tabular}{|c|c|c|c|c|c|c|c|}
\hline $\begin{array}{l}\text { ordem } \\
\text { de } \\
\text { import. }\end{array}$ & ítem & competências & média & d.p & $\min$ & $\max$ & $\mathbf{N}$ \\
\hline $1^{o}$ & 09 & $\begin{array}{l}\text { Comprometer-se com a Unidade, } \\
\text { dedicando-se pessoalmente com a } \\
\text { consecução dos seus objetivos }\end{array}$ & 5,00 & 0,00 & 5 & 5 & 27 \\
\hline $2^{o}$ & 02 & $\begin{array}{c}\text { Enxergar cada usuário do serviço como } \\
\text { um cliente cidadão. }\end{array}$ & 4,97 & 0,18 & 4 & 5 & 30 \\
\hline $3^{\circ}$ & 19 & $\begin{array}{c}\text { Atuar de forma ética, observando os } \\
\text { princípios da impessoalidade e da } \\
\text { moralidade }\end{array}$ & 4,97 & 0,18 & 4 & 5 & 30 \\
\hline $4^{\circ}$ & 03 & $\begin{array}{l}\text { Ser proativo no desempenho de suas } \\
\text { funções }\end{array}$ & 4,93 & 0,25 & 4 & 5 & 30 \\
\hline $5^{\circ}$ & 20 & $\begin{array}{l}\text { Agir de acordo com os princípios da } \\
\text { legalidade e da publicidade. }\end{array}$ & 4,93 & 0,25 & 4 & 5 & 30 \\
\hline $6^{\circ}$ & 21 & $\begin{array}{c}\text { Ter conhecimentos específicos sólidos } \\
\text { em sua área de atuação }\end{array}$ & 4,87 & 0,34 & 4 & 5 & 30 \\
\hline $7^{\circ}$ & 23 & $\begin{array}{l}\text { Ter conhecimento de Direito } \\
\text { Constitucional e Administrativo e outros } \\
\text { ramos do direito. }\end{array}$ & 4,87 & 0,34 & 4 & 5 & 30 \\
\hline $8^{\circ}$ & 01 & $\begin{array}{l}\text { Transmitir valores aos membros de sua } \\
\text { equipe }\end{array}$ & 4,86 & 0,35 & 4 & 5 & 30 \\
\hline $9^{\circ}$ & 12 & $\begin{array}{c}\text { Administrar conflitos, mediando } \\
\text { problemas interpessoais relacionados ao } \\
\text { trabalho }\end{array}$ & 4,83 & 0,37 & 4 & 5 & 30 \\
\hline $10^{\circ}$ & 17 & $\begin{array}{c}\text { Focar em resultados com vistas a um } \\
\text { ambiente de trabalho produtivo }\end{array}$ & 4,80 & 0,40 & 4 & 5 & 30 \\
\hline $11^{\circ}$ & 10 & $\begin{array}{l}\text { Negociar com sua equipe, apresentando } \\
\text { ideias, propondo acordos e } \\
\text { compromissos visando à consecução dos } \\
\text { objetivos da organização. }\end{array}$ & 4,79 & 0,61 & 3 & 5 & 29 \\
\hline $12^{\circ}$ & 24 & $\begin{array}{l}\text { Implementar processos de valorização e } \\
\text { reconhecimento das qualidades dos } \\
\text { membros da equipe sob sua supervisão }\end{array}$ & 4,77 & 0,43 & 4 & 5 & 30 \\
\hline $13^{\circ}$ & 26 & $\begin{array}{c}\text { Reconhecer as aspirações, necessidades } \\
\text { e limitações de seus subordinados na } \\
\text { execução das tarefas que lhes são } \\
\text { inerentes. }\end{array}$ & 4,77 & 0,62 & 2 & 5 & 30 \\
\hline
\end{tabular}


Id on Line Revista Multidisciplinar e de Psicologia

Id on Line Revista Multidisciplinar e de Psicologia

\begin{tabular}{|c|c|c|c|c|c|c|c|}
\hline $14^{\circ}$ & 6 & $\begin{array}{c}\text { Incrementar processo de comunicação } \\
\text { que propicie a colaboração entre as } \\
\text { pessoas }\end{array}$ & 4,77 & 0,43 & 4 & 5 & 30 \\
\hline $15^{\circ}$ & 14 & $\begin{array}{c}\text { Monitorar os desempenhos individuais, } \\
\text { baseado nos padrões de atuação } \\
\text { estabelecidos }\end{array}$ & 4,73 & 0,52 & 3 & 5 & 30 \\
\hline $16^{\circ}$ & 4 & $\begin{array}{l}\text { Desenvolver ações que promovam } \\
\text { trabalhos conjuntos, encontros de } \\
\text { avaliação, troca de experiências, } \\
\text { compartilhamento do conhecimento por } \\
\text { meio de capacitações periódicas. }\end{array}$ & 4,73 & 0,52 & 3 & 5 & 30 \\
\hline $17^{\circ}$ & 27 & $\begin{array}{l}\text { Ser paciente quanto às suas aspirações } \\
\text { pessoais dentro do seu órgão }\end{array}$ & 4,69 & 0,66 & 3 & 5 & 29 \\
\hline $18^{\circ}$ & 13 & $\begin{array}{c}\text { Analisar criticamente dados, } \\
\text { informações e demandas apresentadas à } \\
\text { área sob sua supervisão ou área de } \\
\text { atuação. }\end{array}$ & 4,63 & 0,49 & 4 & 5 & 30 \\
\hline $19^{\circ}$ & 8 & $\begin{array}{l}\text { Implementar inovações e mudanças nos } \\
\text { processos de gestão da Unidade } \\
\text { Judiciária. }\end{array}$ & 4,63 & 0,61 & 3 & 5 & 30 \\
\hline $20^{\circ}$ & 22 & $\begin{array}{l}\text { Conhecer as peculiaridades do } \\
\text { funcionamento do TJPE/TRF/TJBA } \\
\text { (trâmite de processos, relacionamento } \\
\text { entre as áreas administrativa e } \\
\text { legislativa, atribuições de cada órgão). }\end{array}$ & 4,60 & 0,56 & 3 & 5 & 30 \\
\hline $21^{\circ}$ & 15 & $\begin{array}{c}\text { Monitorar o desempenho coletivo, } \\
\text { baseado nos padrões de atuação } \\
\text { estabelecidos }\end{array}$ & 4,60 & 0,81 & 1 & 5 & 30 \\
\hline $22^{\circ}$ & 18 & $\begin{array}{c}\text { Criar ambiente propício à disseminação } \\
\text { de novos conhecimentos e tecnologias } \\
\text { para a sua área de atuação }\end{array}$ & 4,53 & 0,89 & 1 & 5 & 30 \\
\hline $23^{\circ}$ & 7 & $\begin{array}{l}\text { Identificar novas tendências de gestão no } \\
\text { ambiente externo visando adotá-las na } \\
\text { Unidade }\end{array}$ & 4,50 & 0,57 & 3 & 5 & 28 \\
\hline $24^{\circ}$ & 5 & $\begin{array}{c}\text { Estabelecer parcerias com as outras } \\
\text { unidades judiciárias }\end{array}$ & 4,50 & 0,57 & 3 & 5 & 30 \\
\hline $25^{\circ}$ & 25 & $\begin{array}{l}\text { Ser capaz de identificar alternativas de } \\
\text { soluções diante de problemas, levando } \\
\text { em conta os valores do } \\
\text { TJPE/TRF/TJBA, custos e recursos. }\end{array}$ & 4,47 & 1,00 & 1 & 5 & 30 \\
\hline $26^{\circ}$ & 16 & $\begin{array}{l}\text { Utilizar-se dos meios de comunicação } \\
\text { virtual (redes sociais, por exemplo) } \\
\text { como ferramenta para a efetividade no } \\
\text { desempenho de suas funções. }\end{array}$ & 4,33 & 0,88 & 2 & 5 & 30 \\
\hline $27^{\circ}$ & 11 & $\begin{array}{l}\text { Negociar com equipes de outras } \\
\text { unidades judiciárias, apresentando } \\
\text { ideias, propondo acordos e } \\
\text { compromissos visando a consecução dos } \\
\text { objetivos da organização. }\end{array}$ & 4,29 & 0,65 & 3 & 5 & 29 \\
\hline
\end{tabular}

Fonte: dados da pesquisa.

Por meio da tabela podemos perceber o alto índice das notas referentes à importância, sendo que não houve nenhuma nota abaixo de 4,00, num intervalo em que a nota máxima era 5,00. Esse fato demonstra que realmente as competências relacionadas fazem parte do cotidiano dos gestores dos 
Id on Line Revista Multidisciplinar e de Psicoloqia

Id on Line Revista Multidisciplinar e de Psicologia

órgãos participantes da pesquisa, quais sejam, Tribunal de Justiça de Pernambuco, Tribunal de Justiça da Bahia e Tribunal Regional Federal da $5^{\text {a }}$ Região.

Por ordem de pontuação pode-se verificar que as cinco competências com mais pontuação, ou seja, consideradas pelos respondentes como mais importantes tem haver, primeiro com o senso de comprometimento dos gestores com os objetivos da instituição que é prestação jurisdicional célere e eficaz do judiciário, com nota máxima atribuída por todos os respondentes e consequentemente com desvio padrão zero. O que demonstra a importância de comprometer-se com a atividade desenvolvida. Nesse sentido, Oliveira et. al. (2014) afirmam que colaboradores comprometidos e satisfeitos é a solução mais estratégica para a obtenção das finalidades organizacionais. Servidores competentes, comprometidos e conscientes é, primeiramente, um assunto social, já que tem em vista à constituição de uma sociedade mais imparcial, onde prevaleçam os valores sociais, a moral, a importância do cidadão e o compromisso com o serviço público.

Segundo, com o atendimento de qualidade ao usuário da justiça, com média de nota de 4,97 e um desvio padrão muito próximo a zero, ou seja, 0,18 , indicando que os valores atribuídos a essa competências estão muito próximo da média, com muito pouca variância. Esse fato reforça o que Falce et. al. (2014) frisam ao dizer que as organizações do setor público não são imunes às revoluções que estão ocorrendo na área comercial na última década. Surge a necessidade de estarem preparadas para a revolução da prestação de serviços e da boa prestação jurisdicional. Os gestores são levados a ter esse pensamento, pois são eles os fomentadores da boa prestação dos serviços no judiciário.

E terceiro, ainda dentre as cinco julgadas mais importantes pelos gestores dos três órgãos pesquisados estão as competências decorrentes da Constituição Federal, conforme estatuído no caput do artigo 37: "A administração pública direta e indireta de qualquer dos Poderes da União, dos Estados, do Distrito Federal e dos Municípios obedecerá aos princípios de legalidade, impessoalidade, moralidade, publicidade e eficiência ...", quais sejam, atuar de forma ética, observando os princípios da impessoalidade e da moralidade com médias 4,97 e desvio padrão 0,18 e agir de acordo com os princípios da legalidade e da publicidade, com média 4,93 e desvio padrão 0,25. Isso denota uma nítida mudança no pensamento dos que fazem a Administração Pública no Brasil.

De fato a gestão no judiciário demonstra estar incorporada aos reclamos da nova administração pública, como leciona Modesto (2.000, p. 68):

A boa gestão da coisa pública é obrigação inerente a qualquer exercício da função administrativa e deve ser buscada nos limites estabelecidos pela lei. A função administrativa é sempre atividade finalista, exercida em nome e em favor de terceiros, razão pela qual exige legalidade, impessoalidade, moralidade, responsabilidade, publicidade e eficiência dos seus exercentes. O exercício regular da função administrativa, numa democracia representativa, repele não apenas o capricho e o arbítrio, mas também a negligência e a ineficiência, pois ambos violam os interesses tutelados na lei. 
Id on Line Revista Multidisciplinar e de Psicologia

Id on Line Revista Multidisciplinar e de Psicologia

A $6^{\mathrm{a}}$ e a $7^{\mathrm{a}}$ competências mais bem avaliadas, (ter conhecimentos específicos sólidos em sua área de atuação e ter conhecimento de Direito Constitucional e Administrativo e outros ramos do direito), com média e desvio padrão iguais, respectivamente, 4,87 e 0,34, demonstra que os gestores avaliam a apropriação dos conhecimentos relacionados aos processos de trabalho dentro do judiciário como essenciais para desenvolvimento de suas atividades, inclusive com o conhecimento do ordenamento jurídico.

Da $8^{\mathrm{a}}$ até a $15^{\mathrm{a}}$, demonstram que os gestores se preocupam com a parte propriamente dita de gestão de equipes corroborando com o pensamento de Gayotto e Domingues (1995), quando põe como relevante a importância que se dá à busca do espírito de coletividade e coordenação com a finalidade de fomentar a tomada de decisão da equipe, para que se tenha um grupo coeso e influenciado positivamente pelo líder, o qual provoca o interesse nos liderados em aprender recursos técnicos e teóricos para resolver os problemas e efetuar melhorias. Com médias e desvios padrões que variam entre 4,86 e 4,73 e desvios pardrões próximos a zero, ou seja, variam entre 0,35 e 0,62 . A proatividade dos servidores depende muito da atitude dos gestor, o qual deve buscar a transformação constante dos liderados na busca do autodesenvolvimento, pois de acorco com Cruz et al (2015), gestores transformacionais motivam seus seguidores e conseguem fazer com que trabalhem além do que originalmente estavam destinados a trabalhar.

O comportamento gerencial transforma os liderados e os inspiram a irem além de suas expectativas. O despertar do espírito de time passa pela mão do gestor. Percebe-que os gestores do judiciário consideram muito importante a abertura para negociação com o grupo, dando oportunidade ao liderados de expor suas ideias e assim colaborar também intelectualmente para o alcance dos objetivos da instituição. Essa abertura faz parte do processo de valorização da equipe, ítem muito valorizado pelos gestores na pesquisa.

A classificação da competência referente ao aprimoramento da capacidade da equipe, classificada na $16^{\mathrm{a}}$ posição, com média de 4,73 e desvio padrão 0,52 , destaca que os gestores do Judiciário reconhecem a necessidade de estarem em constante aperfeiçoamento deles próprios e dos subordinados por meio das capacitações oferecidas pelos órgãos.

As competências gerenciais tidas como menos importantes para os gestores do judiciário, que culmina com a competência pior avaliada, na classificação 27 , com média 4,29 e desvio padrão 0,65 , qual seja "negociar com equipes de outras unidades judiciárias, apresentando ideias, propondo acordos e compromissos visando a consecução dos objetivos da organização", tem a ver com o ambiente externo à unidade de trabalho. Isso se dá, talvez pela cultura das unidades judiciárias em centralizar-se na figura do magistrado e das atividades rotineiras, e estar alheio aos processos gerais de trabalho da instituição. Nota-se que essa questão deve ser trabalhada, pois poderia haver mais troca de experiências na adoção de boas práticas cartorárias. 
Id on Line Revista Multidisciplinar e de Psicoloqia

Id on Line Revista Multidisciplinar e de Psicologia

\section{Análise do Domínio dos Gestores em Relação às Competências}

Em relação ao domínio que possuem das competências gerenciais, os gestores do Judiciário apresentaram as médias e desvios-padrão constantes na tabela abaixo, que apresenta as competências em ordem decrescente da média computada, isto é, da de maior domínio até a de menor domínio.

Tabela 2 - Domínio das competências pelos gestores do Judiciário

\begin{tabular}{|c|c|c|c|c|c|c|c|}
\hline $\begin{array}{l}\text { ordem de } \\
\text { domínio }\end{array}$ & ítem & competências & média & d.p & $\min$ & $\max$ & $\mathbf{N}$ \\
\hline $1^{o}$ & 19 & $\begin{array}{c}\text { Atuar de forma ética, observando os } \\
\text { princípios da impessoalidade e da } \\
\text { moralidade }\end{array}$ & 4,73 & 0,52 & 3 & 5 & 30 \\
\hline $2^{\circ}$ & 20 & $\begin{array}{c}\text { Agir de acordo com os princípios da } \\
\text { legalidade e da publicidade. }\end{array}$ & 4,69 & 0,80 & 1 & 5 & 29 \\
\hline $3^{\circ}$ & 02 & $\begin{array}{l}\text { Enxergar cada usuário do serviço como } \\
\text { um cliente cidadão. }\end{array}$ & 4,66 & 0,48 & 4 & 5 & 29 \\
\hline $4^{\circ}$ & 09 & $\begin{array}{l}\text { Comprometer-se com a Unidade, } \\
\text { dedicando-se pessoalmente com a } \\
\text { consecução dos seus objetivos }\end{array}$ & 4,63 & 0,62 & 3 & 5 & 27 \\
\hline $5^{\circ}$ & 03 & $\begin{array}{l}\text { Ser proativo no desempenho de suas } \\
\text { funções }\end{array}$ & 4,43 & 0,72 & 3 & 5 & 30 \\
\hline $6^{\circ}$ & 10 & $\begin{array}{l}\text { Negociar com sua equipe, apresentando } \\
\text { ideias, propondo acordos e } \\
\text { compromissos visando à consecução } \\
\text { dos objetivos da organização. }\end{array}$ & 4,41 & 0,73 & 2 & 5 & 29 \\
\hline $7^{\circ}$ & 17 & $\begin{array}{c}\text { Focar em resultados com vistas a um } \\
\text { ambiente de trabalho produtivo }\end{array}$ & 4,28 & 0,75 & 3 & 5 & 29 \\
\hline $8^{\circ}$ & 01 & $\begin{array}{l}\text { Transmitir valores aos membros de sua } \\
\text { equipe }\end{array}$ & 4,28 & 0,70 & 3 & 5 & 29 \\
\hline $9^{\circ}$ & 21 & $\begin{array}{l}\text { Ter conhecimentos específicos sólidos } \\
\text { em sua área de atuação }\end{array}$ & 4,17 & 0,74 & 3 & 5 & 30 \\
\hline $10^{\circ}$ & 14 & $\begin{array}{c}\text { Monitorar os desempenhos individuais, } \\
\text { baseado nos padrões de atuação } \\
\text { estabelecidos }\end{array}$ & 4,17 & 0,83 & 2 & 5 & 30 \\
\hline $11^{\circ}$ & 27 & $\begin{array}{l}\text { Ser paciente quanto às suas aspirações } \\
\text { pessoais dentro do seu órgão }\end{array}$ & 4,14 & 0,87 & 2 & 5 & 29 \\
\hline $12^{\circ}$ & 23 & $\begin{array}{c}\text { Ter conhecimento de Direito } \\
\text { Constitucional e Administrativo e } \\
\text { outros ramos do direito. }\end{array}$ & 4,11 & 0,73 & 3 & 5 & 28 \\
\hline $13^{\circ}$ & 12 & $\begin{array}{c}\text { Administrar conflitos, mediando } \\
\text { problemas interpessoais relacionados } \\
\text { ao trabalho }\end{array}$ & 4,10 & 0,66 & 3 & 5 & 30 \\
\hline $14^{\circ}$ & 26 & $\begin{array}{c}\text { Reconhecer as aspirações, necessidades } \\
\text { e limitações de seus subordinados na } \\
\text { execução das tarefas que lhes são } \\
\text { inerentes. }\end{array}$ & 4,10 & 0,88 & 2 & 5 & 30 \\
\hline $15^{\circ}$ & 15 & $\begin{array}{c}\text { Monitorar o desempenho coletivo, } \\
\text { baseado nos padrões de atuação } \\
\text { estabelecidos }\end{array}$ & 3,97 & 0,98 & 1 & 5 & 29 \\
\hline $16^{\circ}$ & 18 & $\begin{array}{c}\text { Criar ambiente propício à disseminação } \\
\text { de novos conhecimentos e tecnologias } \\
\text { para a sua área de atuação }\end{array}$ & 3,96 & 0,88 & 2 & 5 & 28 \\
\hline $17^{\circ}$ & 13 & $\begin{array}{l}\text { Analisar criticamente dados, } \\
\text { informações e demandas apresentadas à }\end{array}$ & 3,93 & 0,94 & 1 & 5 & 30 \\
\hline
\end{tabular}


Id on Line Revista Multidisciplinar e de Psicologia

Id on Line Revista Multidisciplinar e de Psicologia

\begin{tabular}{|c|c|c|c|c|c|c|c|}
\hline & & $\begin{array}{l}\text { área sob sua supervisão ou área de } \\
\text { atuação. }\end{array}$ & & & & & \\
\hline $18^{\circ}$ & 25 & $\begin{array}{l}\text { Ser capaz de identificar alternativas de } \\
\text { soluções diante de problemas, levando } \\
\text { em conta os valores do } \\
\text { TJPE/TRF/TJBA, custos e recursos. }\end{array}$ & 3,90 & 0,99 & 1 & 5 & 30 \\
\hline $19^{\circ}$ & 16 & $\begin{array}{l}\text { Utilizar-se dos meios de comunicação } \\
\text { virtual (redes sociais, por exemplo) } \\
\text { como ferramenta para a efetividade no } \\
\text { desempenho de suas funções. }\end{array}$ & 3,87 & 1,30 & 1 & 5 & 30 \\
\hline $20^{\circ}$ & 22 & $\begin{array}{c}\text { Conhecer as peculiaridades do } \\
\text { funcionamento do TJPE/TRF/TJBA } \\
\text { (trâmite de processos, relacionamento } \\
\text { entre as áreas administrativa e } \\
\text { legislativa, atribuições de cada órgão). }\end{array}$ & 3,70 & 1,08 & 1 & 5 & 30 \\
\hline $21^{\circ}$ & 24 & $\begin{array}{l}\text { Implementar processos de valorização e } \\
\text { reconhecimento das qualidades dos } \\
\text { membros da equipe sob sua supervisão }\end{array}$ & 3,67 & 1,06 & 2 & 5 & 30 \\
\hline $22^{\circ}$ & 8 & $\begin{array}{c}\text { Implementar inovações e mudanças nos } \\
\text { processos de gestão da Unidade } \\
\text { Judiciária. }\end{array}$ & 3,61 & 1,03 & 1 & 5 & 28 \\
\hline $23^{\circ}$ & 6 & $\begin{array}{c}\text { Incrementar processo de comunicação } \\
\text { que propicie a colaboração entre as } \\
\text { pessoas }\end{array}$ & 3,60 & 1,06 & 1 & 5 & 30 \\
\hline $24^{\circ}$ & 7 & $\begin{array}{c}\text { Identificar novas tendências de gestão } \\
\text { no ambiente externo visando adotá-las } \\
\text { na Unidade }\end{array}$ & 3,46 & 1,10 & 1 & 5 & 30 \\
\hline $25^{\circ}$ & 5 & $\begin{array}{c}\text { Estabelecer parcerias com as outras } \\
\text { unidades judiciárias }\end{array}$ & 3,27 & 1,31 & 1 & 5 & 30 \\
\hline $26^{\circ}$ & 4 & $\begin{array}{l}\text { Desenvolver ações que promovam } \\
\text { trabalhos conjuntos, encontros de } \\
\text { avaliação, troca de experiências, } \\
\text { compartilhamento do conhecimento por } \\
\text { meio de capacitações periódicas. }\end{array}$ & 3,10 & 1,06 & 1 & 5 & 30 \\
\hline $27^{\circ}$ & 11 & $\begin{array}{l}\text { Negociar com equipes de outras } \\
\text { unidades judiciárias, apresentando } \\
\text { ideias, propondo acordos e } \\
\text { compromissos visando a consecução } \\
\text { dos objetivos da organização. }\end{array}$ & 3,04 & 0,96 & 1 & 5 & 28 \\
\hline
\end{tabular}

Fonte: dados da pesquisa.

Em relação ao domínio que os indicam ter sobre as competências, observa-se que as médias relativas ao dominío dos gestores do judiciário quanto às competências relacionadas ficaram abaixo das notas atribuídas às mesmas competências quanto à importância. No entanto nenhuma das competências teve nota média abaixo de 3, num intervalo de mínima 1 e máxima 5.

Observa-se que as cinco competências mais bem pontuadas quanto à importância voltaram a receber as maiores notas quanto ao domínio, revelando que os gestores além de considerarem tais competências importantes, também as dominam, revelando que os gestores se julgam capazes de desempenhá-las com propriedade. Nas duas primeiras colocações estão as competências de maior domínio por parte dos gestores do Judiciário, que são aquelas relacionadas aos princípios 
Id on Line Revista Multidisciplinar e de Psicologia

Id on Line Revista Multidisciplinar e de Psicologia

constitucionais que devem reger a atividade do gestor público, quais sejam, ( $1^{\text {a }}$ colocação), atuar de forma ética, observando os princípios da impessoalidade e da moralidade, com média 4,73 e desvio padrão de 0,52 e ( $2^{\mathrm{a}}$ colocação), agir de acordo com os princípios da legalidade e da publicidade com média 4,69 e desvio padrão 0,80 . Essas competências figuram na tabela de importância na $3^{\mathrm{a}}$ e $5^{\mathrm{a}}$ colocações, respectivamente.

A $3^{\text {a }}$ competência mais bem posicionada de domínio dos respondentes, enxergar cada usuário do serviço como um cliente cidadão, figura com média 4,66 e desvio padrão 0,48 , demonstrando que os gestores entendem que dominam bem a forma de administrar do novo modelo de gerencialismo no serviço público, onde o a satisfação do cliente deve ser um objetivo perseguido pela instituição. De acordo com a literatura, na visão de Falce et al (2014), os critérios de excelência, incluídos a satisfação do cliente/cidadão, são muito importantes, e a sua percepção são fundamentais para ajudar no alcance das metas da organização.

Nas posições $4^{\mathrm{a}}$ a $7^{\mathrm{a}}$ encontram-se as competências voltadas para o comprometimento pessoal para que as respostas tão almejadas pelos usuários da justiça, no sentido de que a resolução dos seus conflitos sociais sejam dadas com celeridade. Com ações objetivas e operacionais, tipo comprometerse, ser proativo, negociar com a equipe, focar em resultados. As médias e o desvio padrão variam respectivamente entre 4,63 e 4,28; 0,62 e 0,75, demonstrando o alto grau de comprometimento pessoal dos gestores não apenas no querer fazer, mas também no poder fazer com habilidade e conhecimento de causa. como bem frisou Zarifian (2001), é a articulação tridimensional que envolve conhecimentos, habilidades e atitudes, ou seja, é o saber, o quê e por que faz, de forma proativa.

A competência classificada na $8^{\mathrm{a}}$ posição ( transmitir valores aos membros de sua equipe) revela que os gestores se sentem confortáveis e prontos para integrar os membros da equipe por meio do compartilhamento de seus conhecimentos. Esse conceito de integração é bem explanado por Le Boterf (2003), ao dizer que o desenvolvimento de uma competência coletiva depende do conhecimento compartilhado para coagir e coproduzir. Le Boterf (2003) ainda diz que a existência de um espírito colaborativo é condição para a construção de um saber coletivo. Nesse sentido as pessoas unem suas diferenças em um sentido de complementaridade, além de buscarem obter juntas os conhecimentos, como um conjunto integrado. Oliveira et al (2015) apud Schein (2009), diz que a cultura se inicia quando os líderes impõem seus valores e premissas a um grupo, que será mantida dentro da organização por um tempo mais longo, servindo até como instrumento de poder.

Da mesma forma que as competências voltadas para a integração com os outros setores diversos da unidade judiciária do respondente foram consideradas as menos importantes, estas mesmas competências figuraram como de pouco domínio pelos gestores, talvez revelando a lacuna de competências existentes, o que gera a necessidade de capacitação voltada para essa integração, no sentido de agregação de experiências externas ao ambiente de trabalho do respondente. As competências supramencionadas estão nas três últimas colocações de domínio dos gestores com 
Id on Line Revista Multidisciplinar e de Psicologia

Id on Line Revista Multidisciplinar e de Psicologia

médias variando entre 3,27 e 3,04 e desvio padrão muito alto, variando entre 1,31 e 0,96, índices não tão próximos de zero, demonstrando que não há muito coesão de pensamento entre os participantes da pesquisa.

\section{Conclusões}

O desígnio deste trabalho consistiu em analisar as competências dos gestores do Judiciário do sertão pernambucano e baiano, distribuídas e classificadas quanto à importância e ao domínio que os gestores acreditam possuir dessas competências.

$\mathrm{O}$ questionário utilizado teve as suas perguntas baseadas na literatura sobre o tema proposto e foi dirigido aos diretores/chefes de secretarias das unidades judiciárias do Tribunal de Justiça de Pernambuco, Tribunal de Justiça da Bahia e Tribunal Regional Federal da $5^{\text {a }}$ Região, com a finalidade de diagnosticar as competências existentes nos três órgãos, bem assim as lacunas de competências necessárias para que a instituição esteja no caminho de transformação da nova forma de gerencialismo no serviço público.

Por meio dos resultados obtidos a Direção dos órgãos pesquisados podem promover ações no sentido de planejar e executar cursos de capacitação específicos para melhorar a prestação jurisdicional.

Considerando que na maioria das comarcas pesquisadas existe apenas uma unidade judiciária e portanto um gestor, o número de respondentes da pesquisa foi considerado satisfatório. Para termos o máximo possível de feedback dos pesquisados, o contato para entrega e explicação do questionário foi realizado de forma pessoal, a não ser das comarcas mais distantes, às quais fizemos o contato via telefone para posterior envio dos questionário por e-mail. Com isso tivemos um aproveitamento de $88,23 \%$, pois dos 34 gestores contactados, 30 responderam e enviaram os questionários, inclusive com poucas perguntas sem respostas.

Os questionários foram enviados para 34 unidades judiciárias no sertão pernambucano, nas cidades de Cabrobó, Orocó, Lagoa Grande, Ouricuri, Afrânio, Araripina, Petrolina e ainda na Cidade de Juazeiro-BA, envolvendo 34 gestores. Nas cidades de Petrolina e Juazeiro-BA os questionários foram entregues de forma pessoal, com o intuito de obter o máximo de respostas possíveis, tendo em vista haver poucas Unidades Judiciárias e consequentemente poucos Diretores/chefes de secretarias para a amostra da pesquisa.

30 dos 34 gestores contactados responderam os questionários, ou seja, tivemos um aproveitamento de $88,23 \%$. Esse percentual torna possível a análise das competências e consenquetemente traz à tona as lacunas que deverão ser trabalhadas visando o desenvolvimento da gestão no judiciário. 
Id on Line Revista Multidisciplinar e de Psicologia

Id on Line Revista Multidisciplinar e de Psicologia

Os 30 respondentes gestores consideraram todas as competências apresentadas como sendo importantes para o desenvolvimento das atividades no judiciário. Avaliaram com médias que variaram entre 4,29 e 5,00, demonstrando que todas as competências foram acertadamente incluídas no questionário, pois dizem respeito às atividades laborais próprias das instituição.

Da mesma forma ao analisar os dados percebemos que as competências relativas ao domínio que os gestores possuem sobre as competências apresentadas no questionário também se apresentaram em nível satisfatório, embora que, com médias abaixo das apresentadas no quesito importância. No entanto, com médias acima de 3,00 permitir entender que os gestores do judiciário apresentam bom nível de capacitação. Como demonstra a análise dos dados sociodemográficos, onde $90 \%$ possuem no mínimo o ensino superior completo, e o restante dos $10 \%$, estão na instituição há mais de dez anos, portanto com bastante experiência nas atividades necessárias ao judiciário.

Notou-se que as competências mais valorizadas são aquelas que dizem respeito à prestação do serviço público nos moldes da nova forma de administração pública, com respeito aos cidadãos, sendo estes tratados como os mais importantes na cadeia da prestação dos serviços públicos. Há um entendimento geral entre os respondentes, demonstrado pelos cálculos dos desvios padrões, sempre próximo a zero, de que as organizações não-comprometidas com a satisfação do cidadão não prosperam e não irão prosperar, e possivelmente nem irão sobreviver, pois a satisfação com o atendimento é o resultado de um encontro dinâmico, no qual o usuário da justiça/consumidor avalia tanto o processo quanto o resultado, atribuindo valor a ambos. ( Saraiva e Campelo 2000)

Quanto às lacunas de competências apresentadas, destacaram-se aquelas voltadas para o ambiente externo à unidade de trabalho. Resultado da cultura das unidades judiciárias em centralizarse na figura do magistrado e das atividades rotineiras, e estar alheio aos processos gerais de trabalho da instituição. Razão por que essa é uma questão que deve ser trabalhada, pois poderia haver mais troca de experiências na adoção de boas práticas cartorárias. Para Zarifian (2001, p 72), "a competência é um entendimento prático de situações que se apoia em conhecimentos adquiridos e os transforma na medida em que aumenta a diversidade de situações". O conhecimento adquirido pelo gestor no ambiente profissional, seja das atividades interna unidades judiciária, seja das atividades externas inerentes à instituição, será fundamental para o alcance dos objetivos gerais da instituição. Essa relação de troca entre as unidades judiciárias é importante para o desenvolvimento da instituição, pois o uso da visão macro organizacional é fundamental para qualquer equipe, tendo em vista que conhecerão como e onde sua tarefa específica comprometem e cooperam com os objetivos da instituição. Silva e Rabelo (2003), citando Morgan (1995:49), faz uma analogia com os sistemas orgânicos e demonstra que independente de ser uma célula do organismo complexo ou uma população de organismos, existe “... um contínuo processo de trocas com os seus ambientes. Essa troca é crucial para a manutenção da vida e forma do sistema, uma vez que a interação com o ambiente é fundamental à automanutenção". 
Id on Line Revista Multidisciplinar e de Psicoloqia

Id on Line Revista Multidisciplinar e de Psicologia

Nesse contexto, urge a necessidade de capacitações para que os gestores e servidores em geral conheçam a política de trabalho da instituição, de forma que tenha um conhecimento mais complexo dos objetivos propostos pelo órgão em que ele é vinculado e assim possam, por meio das trocas, agregar valor às tarefas do judiciário.

Quanto às demais competências, é importante a promoção de capacitações a fim de que os gestores estejam sempre atualizados e prontos para as mudanças que são inerentes em qualquer instituição.

\section{Referências}

ALBUQUERQUE, Lindolfo Galvão e OLIVEIRA, Patrícia Morila. Competências ou Cargos: uma análise das tendências das bases para o instrumental de recursos humanos. Caderno de Pesquisas em Administração, São Paulo, v. 08, nº 4, outubro/dezembro 2001.

ALMEIDA, A. M. P. \& MOTTA, F. M. V. O desenvolvimento de Competências Gerenciais como fator de vantagem competitiva: um estudo de caso em uma empresa estatal de telecomunicações. 2012. Disponível http://www.angrad.org.br/_resources/files/_modules/producao/producao_635_201212051834228e9c.p df. Acessado em 17/03/2016.

BRASIL. Decreto n ${ }^{\mathbf{0}}$ 5.707, de 23 de Fevereiro de 2006. Institui a Política e as Diretrizes para o Desenvolvimento de Pessoal da administração pública federal direta, autárquica e fundacional, e regulamenta dispositivos da Lei no 8.112, de 11 de dezembro de 1990. Disponível em: http://www.planalto.gov.br/ccivil_03/_Ato2004-2006/2006/Decreto/D5707.htm. Acesso em: 16 de dezembro de 2015.

BOWDITCH, J. L.; BUONO, A. F. Elementos do comportamento organizacional. São Paulo: Pioneira, 2002.

BOURDIEU, Pierre; O poder Simbólico. Tradução Fernando Tomaz ( Português de Portugal) - $7^{a}$ Ed. - Rio de Janeiro; Bertrand Brasil , 2004. 322p.)

CUNHA, Cláudio Alberto Gusmão. Legitimidade, certeza do direito e justiça. Revista dos Mestrandos em Direito Econômico da UFBA, Salvador, n. 7, p. 133-155, jan./dez. 1999.

CUNHA, M. G.; BEZERRA, R. O.; MEDEIROS, E. M. B. Liderança por competência: eficácia do líder após mudança de cenário. RAUnP - Revista Eletrônica do Mestrado Profissional em Administração da Universidade Potiguar, v. 6, n. 2, p. 89-100, 2014.

DANTAS, Débora et al. Um olhar sobre as competências individuais. 2011. Disponível em http://www.recantodasletras.com.br/artigos/3349184. Acesso em 24/01/2012.

DUTRA. J. S. Competências: conceitos e instrumentos para a gestão de pessoas na empresa moderna.São Paulo: Atlas, 2004. 
Id on Line Revista Multidisciplinar e de Psicoloqia

Id on Line Revista Multidisciplinar e de Psicologia

CRUZ, A. P. C.; FREZATTI, F.; BIDO, D. S. Estilo de Liderança, Controle Gerencial e Inovação: Papel das Alavancas de Controle . Revista de Administração Contemporânea, v. 19, n. 6, p. 772 794, 2015. Disponível em http://www.spell.org.br/documentos/ver/38050/estilo-de-lideranca-controle-gerencial-e-inovacao--papel-das-alavancas-de-controle-. Acessado em 30/03/2016.

FLEURY, M.T., FLEURY, A. Estratégias Empresariais e Formação de Competências: um quebracabeça caleidoscópio da indústria brasileira. $3^{\text {a }}$ Ed. São Paulo: Atlas, 2004.

FALCE, J. L.; MUYLDER, C. F.; PRESSOT, I. M.; TOIVANEN, M. A. B. L. Qualidade no serviço público: um estudo de caso em uma fundação pública em Minas Gerais. Amazônia, Organizações e Sustentabilidade, v. 3, n. 2, p. 43-62, 2014.

GAYOTTO, M. L. C; DOMINGUES I. Liderança: Aprenda a mudar em grupo. $5^{\text {a }}$ ed. Petrópolis, RJ: Vozes, 1995. 98 p.

LAKATOS, E. M.; MARCONI, M. A. Fundamentos de metodologia científica. 7.ed. São Paulo: Atlas, 2010.

LE BOTERF, Guy. Desenvolvendo a competência dos profissionais. Tradução de Patrícia Chittoni Ramos Reuillard. Porto Alegre: Artmed, 2003.

LE BOTERF, Guy. Competénce et navigation profissionnelle. Paris: Éditions d'Organisatio, 1999.

LIMA, J. O.; SILVA, A. B. Determinantes do desenvolvimento de competências coletivas na gestão de pessoas. Revista de Administração Mackenzie, v. 16, n. 5, p. 41-67, 2015.

MELLO, Carlos (Org.). Métodos quantitativos: pesquisa, levantamento ou survey. Aula 09 da disciplina de metodologia de pesquisa na UNIFEI. Disponível em: <http://www.carlosmello.unifei.edu.br/Disciplinas/Mestrado/PCM-10/Slides-

Mestrado/Metodologia_Pesquisa_2012-Slide_Aula_9_Mestrado.pdf>. Acesso em: 15/03/2016.

MERTENS, Leonard. Competencia laboral: sistemas, surgimiento y modelos. Montevideo: Cinterfor, $1996 . \quad$ Disponíovel em http://www.oei.es/etp/competencia_laboral_sistemas_modelos_mertens.pdf . Acessado em 17/02/2016.

MODESTO, Paulo. Notas para um debate sobre o princípio da eficiência. Revista Interesse Público, Ano 2, ${ }^{\circ}$ 7, julho/setembro/2000, São Paulo: Ed. Nota dez, 2000, páginas 65-75.

OLIVEIRA, Arcelí Ângela Anzolin; COSTA, Gisele Maria Tonin; ZANIVAN, Rafaela Pauletti; Motivação e Comprometimento do Servidor Público Municipal: Uma questão de análise; RACI, Getúlio Vargas, v.8, n.17, jan./jun. 2014. Issn 1809-6212-Disponível em http://www.ideau.com.br/getulio/restrito/upload/revistasartigos/60_1.pdf. Acessado em 28/03/2016.

OLIVEIRA, A. V.; VELOSO, E. F.; TREVISAN, L. N. A transformação do especialista em líder: um estudo de caso em empresa de telecomunicações. Revista Capital Científico - Eletrônica, v. 13, n. 1, p. 41-58, 2015. Disponível em http://www.spell.org.br/documentos/ver/34889/a-transformacao-doespecialista-em-lider--um-estudo-de-caso-em-empresa-de-telecomunicacoes. Acessado em 30/03/2016.

PALHARINI, Francisco de Assis, Recrutamento e seleção de pessoas: fundamentos e tendências.

Disponível em: <http://www.ichf.uff.br/pdf_docs/cadernosichf/CDI88-Palharini

RecrutamentoSelecaoPessoas.pdf > Acesso em 15/03/2016 às 17:46min 
Id on Line Revista Multidisciplinar e de Psicoloqia

Id on Line Revista Multidisciplinar e de Psicologia

SANTOS, Aleksandra Pereira. Competências para a carreira de gestores governamentais: Desenvolvimento e evidências de validade de uma escala - REGE , São Paulo - SP, Brasil, v. 21, n. 1, p. 27-41, jan./mar. 2014.

SANTOS, A. P. D.Competências para a carreira de gestores governamentais: desenvolvimento e evidências de validade de uma escala. Revista de Gestão, v. 21, n. 1, p. 27-41, 2014. Disponível em http://www.spell.org.br/documentos/ver/32301/competencias-para-a-carreira-de-gestores-

governamentais--desenvolvimento-e-evidencias-de-validade-de-uma-escala/i/pt-br. Acessado em $16 / 03 / 2014$

SARAIVA, L. A. S.; CAPELÃO, L. G. F. A nova administração pública e o foco no cidadão: burocracia x marketing?. Revista de Administração Pública, v. 34, n. 2, p. 1-9, 2000. Disponível em http://www.spell.org.br/documentos/ver/12716/a-nova-administracao-publica-e-o-foco-no-cidadao-burocracia-x-marketing- Acessado em 01/04/2016.

SILVA, Francielle Molon; MELLO, Simone Portella Teixeira. Revista do Serviço Público Brasília 62 (2): 167-183 Abr/Jun 2011169 RSP.

SILVA, A. B.; REBELO, L. B. A.; A emergência do pensamento complexo nas organizações. Revista de Administração Pública, v. 37, n. 4, p. 777-796, 2003. Disponível em http://www.spell.org.br/documentos/ver/12342/a-emergencia-do-pensamento-complexo-nasorganizacoes, Acessado em 01/04/2016.

STREIT, C. L. Desenvolvimento de competências individuais comportamentais associadas à inovação na gestão: a contribuição da aprendizagem organizacional. Dissertação (Mestrado em Administração)- Universidade Federal do Rio Grande do Sul, Porto Alegre, 2001.

TEIXEIRA, Rogério Ventura. Gestão de competências: uma análise de competências de gestores da Câmara dos Deputados. 2006. 79 f. Dissertação (Mestrado em Gestão Social e do Trabalho) Universidade de Brasília, Brasília, 2006. Disponível em http://repositorio.unb.br/handle/10482/2220. Acessado em 20/03/2016.

TOMASI, A . Da qualificação à competência: pensando o século XXI. Campinas, SP: Papirus, 2004

ZARIFIAN, P. Objetivo Competência: por uma nova lógica. Tradução Maria Helena C. V. Trylinski. São Paulo: Atlas, 2001.

\section{Como citar este artigo (Formato ABNT):}

SOUZA, F.G.; CASSUNDÉ, F.R.S.A. Um estudo sobre as competências gerenciais na Administração Pública: O caso dos gestores do Judiciário Brasileiro. Id on Line Revista Multidisciplinar e de Psicologia, Julho de 2016, vol.10, n.30, p. 189-210. ISSN 1981-1179.

Recebido: 01/05/2016

Aceito: 06/05/2016 